\title{
Twenty-five Years in History
}

\section{By F. S. Marvin}

KING GEORGE'S reign will always be remembered in history for three, or rather four, unique events of world-wide as well as national importance. It has contained the whole period of the greatest war in history and the more difficult part of the reconstruction which followed it. It has seen the foundation of the League of Nations and its early growth. It has witnessed an unparalleled economic depression from which we are now slowly recovering, and which we hope and believe His Majesty will survive to see completely overcome. Lastly, in the sphere with which NATURE is more specially concerned, the King's reign covers the establishment of the most far-reaching transformation of our ideas of the material universe, for Einstein's ideas gained general acceptance just after the conclusion of the War.

It is one of the ironies of history that the greatest of wars should thus be connected with the name of one of the most pacific of kings. But there was not for a moment any doubt that the King fully sympathised with his people in all the four years of their trial, in spite of the family ties which connected him with the most formidable of their opponents. After the War, one noticed a marked increase in the public affection and esteem for a man whose good qualities at first suffered somewhat from a comparison with the bonhomie and genial character of his father; and when, at the end of 1928, he was for a time laid low by a serious illness, it was clear that he had already won all hearts. Time has only strengthened that position. He is so obviously the good and devoted man, ready to bear everything and do everything for the sake of others, and, above all, for the restoration of the country and its prosperity in peace.

Next to the War, the League of Nations is, of course, the largest political issue of the King's reign. In this matter the King was fortunate in his position, and better guided by political instinct than the contemporary head of the American Republic. He was able, quite impartially, to commend the League as a common interest to all his subjects, whereas it unfortunately became a party issue in the United States. In England, King George could ask all his subjects to give it their support, and, with the aid of Great Britain and the British Dominions, it has already attained considerable success. France too has been a loyal supporter; but, in the British Commonwealth, there was a league within the League without which the effectual functioning of the larger organisation is scarcely thinkable. At the moment, the adhesion of Russia and the close co-operation of the United States do much to set off the temporary abstention of Germany and Japan. The current year, which ushers in the King's jubilee, has seen several instances of the value of the League's work in carrying out the pacification of the world on lines entirely in accordance with the King's life-desire.

The work of social reconstruction, of healing the wounds of war and making provision for a fuller life in future, is still upon us. It was seriously aggravated, at about the time of the King's illness, by the bursting on the world of an economic depression which was as unparalleled in its severity as the War. It does not fall within the scope of this article to discuss the causes of this or the remedies which are now slowly overcoming it. Some of the difficulties no doubt are due to the fact that the resources of science in multiplying the productivity of the earth have for the time outstript our methods of distribution, and national barriers and new notions of national self-sufficiency have hindered the free circulation of the products. But one thing relating to science and arising directly from the War falls to be noticed here. The War stimulated scientific experiment on the mechanical, physical and chemical sides as it had never before been stimulated in history. The evil necessities of the time forced on work in the laboratory, in the forge and in the air which have had many not-evil results. Civil aviation has largely profited from what our engineers devised and our pilots carried out mainly over the Western Front. So also in the chemical laboratories, aiming for the time at the destruction of other men, an activity was developed which has since taken other directions. The Department of Scientific and Industrial Research, which now conducts inquiries into many matters of permanent national concern, dates from this time. It now has its own research stations and promotes the work of twenty-two industrial research associations. One may quite truly -while earnestly desiring a further abatement in the manufacture of arms-consider that most of the swords forged for slaughter have since been turned into ploughshares and pruning hooks.

So strange is the balance of good and evil in life that, while we were all, quite rightly, deploring the extinction of so many young and promising lights of science in the great catastrophe, science itself was taking some of its most prodigious strides forward. 
It will always be remembered in history that the same year which saw the Treaty of Versailles and the establishment of the League of Nations, saw also the confirmation of Einstein's theory of relativity in the eclipse of the sun in 1919. The greatest step towards the permanent peace of the world coincides with the greatest step towards the establishment of the most comprehensive physical conception of the universe. In that eclipse the apparent displacements outwards of the positions of stars in relation to the sun, as shown on photographs of the eclipse, were found to be consistent with Einstein's calculations and confirmatory of his special theory. From that time onward, what had been regarded rather as a private speculation of an eminent man, took rank as the leading conception of a new era of thought. It is now found at the root of all the physical speculations about the material universe which make the more recent part of King George's reign one of the most notable epochs in the history of science.

The new outlook comes home to us more closely at the time of national rejoicing, because so many English and Anglo-Saxon names stand on the record of the advance. Two-Jeans and Eddington -are household words. Within ten years of the confirmation of Einstein's theory, man seemed to have gained a closer insight into the physical constitution of the universe than all the previous centuries had offered. It was shown to be congruous with the nature of the atom as revealed in the laboratory. New lines of development were suggested by which the heavenly bodies had assumed their present form and light. A view was thus attained which looked into the future as well as the past, and knit together what had been thought of as an infinity of space, into the expanding mind of man. This new synthesis was intimately connected with Einstein's theories, and its application, in the interiors of the stars and the remotest recesses of space, was made possible by the extension of photographic and photometric methods. An alliance was set up between work in the laboratory and work with the telescope which has led to the latest discovery of a universal fundamental number, which Sir Arthur Eddington explains in his new book.

It was thought at first that the new views were a revolution, and that Newton was superseded. But Einstein himself never countenanced this conclusion. To him, Newton was merely corrected and supplemented, and new and old thought found their place together in one essentially continuous evolution. But no doubt a shock was given to the finality of Victorian science in more than one respect. The universe of matter was no longer a finite thing, enclosed within an infinity of empty space. It became an expanding finite, full and similar throughout. Moreover, whereas absolute certainty and precision seemed to be given by the old Newtonian synthesis, the new view, coloured by the quantum of Planck, introduced an apparent indeterminacy into the old and apparently rigid laws.

In another respect the progress of science in the new century does not follow precisely the programme anticipated in the nineteenth. Thinking then that the Newtonian synthesis was final, it was commonly expected that the twentieth century would see added to this accomplished fact, another, equally complete and final set of laws, co-ordinating the phenomena of life. Now, in spite of the enormous extension of biology, this attractive prospect has certainly not been realised. Mathematical thinking has gone on pervading wider and wider fields, and gaining the conspicuous triumph which Sir James Jeans has made familiar to all. But biology, though invaded by mathematics and though engaging a constantly larger army of workers, has reached no synthesis comparable to that of Newton for astronomical physics. It has become more and more dispersed and specialised. The Mendelian laws have been added to Darwin's, but the nature of heredity and the cause of variations remain still in the realm of eager inquiry and speculation rather than of ascertained truth. The immediate sequel both of Darwin and of Mendel was rather the setting men to think and examine the details more closely, than the drawing of conclusions from wellestablished principles. Not deduction, but increasing experiment and induction, are still the leading features.

During the War, a school of biologists began to be spoken of as 'neovitalists', of whom the bestknown name is that of Driesch. They were opposed to the idea that, by pressing. on the investigation of the physical and chemical conditions of life, we might ultimately grasp the origin and nature of life itself. Such work is, of course, being incessantly done, and is one of the most prominent features of the biology of the day. But the school of neo-vitalists maintains that life is a thing sui generis and that, however far we may explain its conditions, we can never explain $i t$, any more than we can explain the fact of consciousness by analysing the components of our sensations. Bergson, the most famous philosopher of the period, gave powerful support to this school of thought by developing his conception of an élan vital on the psychological side. On the biological, it revived to some extent the idea of Lamarck that the living being stretched out in the direction of its advantage in life, and that the result of such efforts were transmitted by inheritance from one generation to another. Such transmission is at the moment 
denied by the majority of biologists, but a vigorous school of thinkers, finding their inspiration rather in philosophy than chemistry, are working to reconcile progressive work in biochemistry with the study of life in the concrete. There are indeed signs that the rest of the century may come to justify the glowing prediction of the late Prof. Patrick Geddes, that it would see the triumph of life and be the age of biology. It is already true, in the more general sense, that men accept as a philosophical idea the community of all life and the development of higher forms of life from lower by some process in time which we have still to unravel.

It would be well if one could speak of the acceptance of a community of human life on the planet with as much confidence as the growing consensus of opinion as to its origin. In this matter, while the King's reign is distinguished by the establishment of the League of Nations, it cannot be said that the idea which it embodies or the practices which it exists to promote have made commensurate progress with what we have had to record of the progress of science. In some respects, there has been in recent years an actual setback. Germany and Japan have renounced the League, and the United States, though helpful and friendly, has not formally joined even the Court of International Justice at The Hague. Armaments have lately increased and no effective grouping or control of aviation has yet been effected. There could be no more flagrant instance of the contrast between the unity of thought, which has given man his command of Nature, and the want of unity in his application of it, than this wanton rivalry in military aviation. The most highly scientific means of transport and intercourse still threaten us as the most terrible method of mutual extermination, and the nations refuse an obvious resource to common action, common command, or even a common time-table for pacific purposes. Nothing could better signalise the later years of His Majesty's reign, or be more in keeping with the master-spirit of the man whose life we prize and are now commemorating, than the conclusion of such an agreement. It would be backed by all the scientific opinion of the world, and be the most striking proof of the progress of the reign in its essential quality-the pursuit of peace.

\section{The Structure of the Universe}

\section{By Sir James Jeans, F.R.s.}

$\mathrm{I}^{\mathrm{N}}$ the last quarter of a century, our picture of the astronomical universe has changed almost beyond recognition, and yet we seem to be standing only on the seashore of the great ocean of knowledge.

The geocentric view of the structure of the universe became untenable for thinking men in the year 1610, but in 1910 many astronomers favoured a 'galacto-centric' view, believing that the galactic system was the central and dominating feature of the astronomical universe, with the earth very near to its geometrical centre.

Sir William Herschel had shown that such stars as he could see in his telescope constituted a coinshaped structure, the more distant stars combining to form the faint band of light we call the Milky Way. In the astronomical language of 1910, a few classes of objects-spiral nebulæ and globular star-clusters-were found to 'shun' this plane, but the majority-irregular and planetary nebulæ, blue and Wolf-Rayet stars, eclipsing and Cepheid variables-'favoured' it, ranging themselves about this plane like flies on the two sides of a fly-paper. For this reason the plane of the Milky Way was thought to be fundamental in the structure of the universe.
So far back as 1755, Kant had shown that other views were possible, suggesting that the elliptical nebulæ were not "enormous single stars, but systems of many stars" similar to our own, but at so vast a distance that their light "on account of their immense multitude, reaches us in a uniform pale glimmer".

Herschel adopted this view, speaking of these supposed other systems of stars as "island universes". It fell into disfavour for a time, but Eddington, writing in 1914, remarked that "the hypothesis has recently been revived as regards the spiral nebulæ". He continued: "It must be admitted that direct evidence is entirely lacking as to whether these bodies are within or without the stellar system".

Then Hubble found it possible to measure the sizes and distances of these objects, and the problem was solved. Certain standard objerts are believed to shine with the same intrinsic luminosity wherever they occur in space, so that their apparent faintness at once gives a measure of their distance. Among such standard beacon-lights are Cepheid variables of assigned period, long-period variables, blue stars of assigned spectral type, and novæ at maximum. Examples of most of these standard 